Fetal Diagnosis and Therapy

\title{
A Novel Translational Model of Percutaneous Fetoscopic Endoluminal Tracheal Occlusion - Baboons (Papio spp.)
}

\author{
Giancarlo Mari $^{a} \quad$ Jan Deprest ${ }^{f}$ Mauro Schenone ${ }^{a}$ Scott Jackson ${ }^{b}$ \\ Jacques Samson $^{a}$ Brian Brocato ${ }^{a}$ Danielle Tate ${ }^{a}$ Ryan Sullivan ${ }^{b}$ Garry White \\ Reddy Dhanireddy ${ }^{\mathrm{b}}$ Timothy Mandrell $^{\mathrm{b}}$ Sonali Gupta ${ }^{\mathrm{a}}$ Cezary Skobowjat $^{\mathrm{c}}$ \\ Andrzej Slominskic Harris L. Cohen ${ }^{d}$ Natalia Schlabritz-Loutsevitch ${ }^{a}$ \\ ${ }^{a}$ Division of Maternal and Fetal Medicine, University of Tennessee Health Science Center, Departments of \\ ${ }^{b}$ Comparative Medicine, ${ }^{c}$ Pathology, and d Radiology, University of Tennessee Health Science Center, College of \\ Medicine, Memphis, Tenn., and 'Baboon Resources, Department of Pathology, University of Oklahoma, Oklahoma, \\ Okla., USA; ${ }^{f}$ University of Leuven, Leuven, Belgium
}

\section{Key Words}

Fetoscopic endoluminal tracheal occlusion .

Non-human primates $\cdot$ Fetus $\cdot$ Surgeries

\begin{abstract}
Introduction: Percutaneous fetoscopic endoluminal reversible tracheal occlusion (FETO) was developed to prevent the pulmonary complications of fetal congenital diaphragmatic herniation. There is an urgent need to establish the closest to human translational model of FETO in order to improve fetal outcomes and to determine new clinical approaches and applications. Material and Methods: Seven non-human primates underwent two subsequent surgeries: the first, the FETO in the experimental group $(n=3)$ or sham operation in the control animals (S-FETO, $n=4$ ) at 132-142 days of gestation (dGA); the second, the reversal of occlusion or sham operation at $162 \pm 5 \mathrm{dGA}$. Maternal stress axis, complete blood count, and biochemical parameters were evaluated and newborn tracheal radiography was performed. Results: The
\end{abstract}

average pregnancy duration and neonatal weights in the FETO group did not differ from the animals in the S-FETO group. There was no bleeding or premature fetal membrane rupture during the procedures in any of the baboons. The maximal tracheal width was $7.02 \pm 0.6 \mathrm{~mm}$ in the FETO versus $5.46 \pm 0.6 \mathrm{~mm}$ in S-FETO group. Discussion: This is the very first report of a successful FETO model in non-human primates. Similarities to human tracheomegaly were for the first time documented in any model studied.

(c) 2014 S. Karger AG, Basel

\section{Introduction}

Congenital diaphragmatic hernia $(\mathrm{CDH})$ has an incidence of $1 / 2,000-1 / 5,000$ pregnancies worldwide [1]. The associated perinatal mortality ranges from 10 to $40 \%$ [2]. The cause of mortality is mostly pulmonary hypoplasia and severe pulmonary hypertension [3]. Percutaneous fetoscopic endoluminal tracheal occlusion (FETO) by a

\section{KARGER}

E-Mail karger@karger.com

www.karger.com/fdt
(C) 2014 S. Karger AG, Basel

$1015-3837 / 14 / 0352-0092 \$ 39.50 / 0$ 
Table 1. List of the animals (Papio spp.) and performed procedures

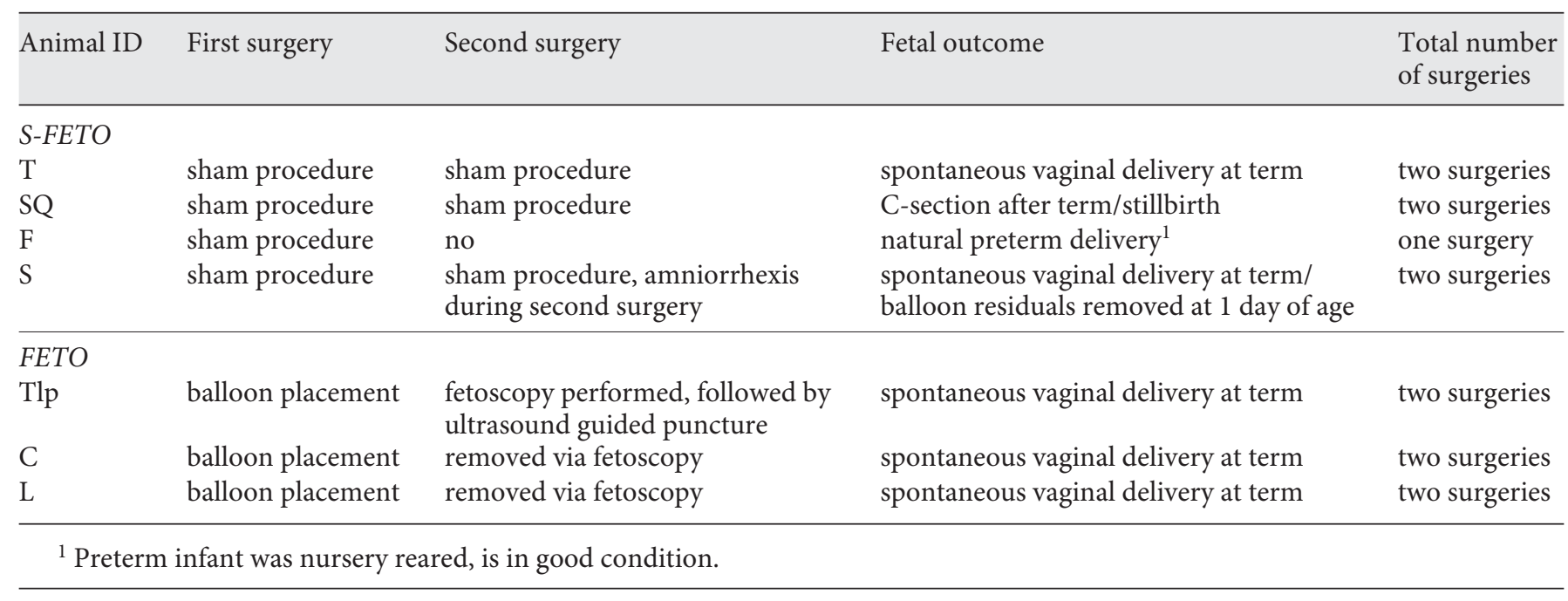

balloon is a promising technique to improve fetal lung growth in the fetuses with $\mathrm{CDH}$ [4]. However, despite the application in humans, there is an urgent need to understand the mechanisms behind this procedure to develop the adjuvant therapies and new approaches in order to decrease long-term and short-term complications of $\mathrm{CDH}$.

Several experimental models have been used to study the effect of tracheal occlusion on fetal lung development including sheep [5, 6], rats [7], mice [8] and rabbits $[9,10]$. Each model has its own advantages. However, the lung development, placental structure and function and thus, the endocrinology of regulation of fetal organs' growth in these animal models differ from primates, including humans [11]. For example, leptin - an important regulator of fetal lung development, is synthesized by the placenta in primates, but not in rodents and ruminants [12].

Non-human primates (NHP) have been used for pregnancy-related research for decades. The similarity to human type of placentation [13], fetal endocrine responses to the manipulation of maternal environment [12], the well-described mechanism of lung development [14], and the similarity to the human fetus make this model ideal for both the development of fetal instrumentation and the study of fetal organogenesis. Baboons (Papio spp.) have been successfully used in models involving repeated cordocenteses $[15,16]$; however, attempts to perform repeated in utero surgical procedures in these species are nonexistent. Here, we describe the development of a baboon model to study the mechanism of FETO influence on fetal lung development.

Percutaneous Fetoscopic Endoluminal Tracheal Occlusion in Baboons

\section{Material and Methods}

\section{Animals Housing and Handling}

Seven time-dated pregnant baboons (Papio hamadryas anubis) were used in this study (age range 6-15 years, weight $17.2 \pm 0.4 \mathrm{~kg}$ ). Animals were transported from the University of Oklahoma Health Sciences Center Baboon Research Resource (Oklahoma, Okla., USA) and housed in a single cage environment at the AALAC approved facilities of the Department of Comparative Medicine, University of Tennessee Health Science Center (UTHSC). Animals received enrichment in the form of video/audio recordings, plastic toys, and fruits/vegetables. They were fed standard Monkey diet (LEO5, Purina, St. Louis, Miss., USA) and given water ad libitum. Animals were constantly monitored with video cameras (Axis M3204 Camera - HD, Axis Communications $A B$, Lund, Sweden) connected through the secure network to the computer desks of the investigators and veterinarians (exacqVision, Fishers, Ind., USA). All procedures were approved by the Animal Care and Use Committee at UTHSC (protocol No. 2330).

\section{Experimental Design}

Following the initial acclimation period of 3 weeks, each animal underwent two subsequent surgeries: the first, FETO in the experimental group $(\mathrm{n}=3)$ or a sham tracheoscopy in the control animals ( $\mathrm{n}=4$, S-FETO); the second, reversal of occlusion or sham tracheoscopy (table 1). The gestational age at first surgery was $137 \pm 5$ days of gestation (dGA; $0.73-0.79$ gestation; the length of the gestation is 180 $\mathrm{dGA})$ and $162 \pm 5 \mathrm{dGA}$ (0.92 gestation) at the second intervention.

\section{Animal Characteristics}

The mean maternal age (MA) and parity (P) did not differ between the FETO $(\mathrm{MA}=9.7 \pm 0.3$ years, $\mathrm{P}=4)$ and the S-FETO ( $\mathrm{MA}=13 \pm 4$ years, $\mathrm{P}=7$ ) groups. One animal in the S-FETO group had previously delivered one stillborn fetus. The average gestational length was calculated for each animal based on the data retrieved from the animal records (table 1). The duration of the current pregnancy was expressed as the percentage of usual gesta- 
tional length for each animal. As an indicator of the gestational length in both groups, this parameter is superior to the gestational age calculated as the number of days spent after the day of conception, since the delivery at term is individual for each animal and ranges from 163 to $190 \mathrm{dGA}$.

\section{Procedural Animal Care}

Preoperative, Operative, and Postoperative Care

On the day prior to surgery food was withheld, but access to water was ad libitum. Ketamine hydrochloride (10 mg/kg; Putney Ketamine $\mathrm{HCl}^{\circledR}$ for Injection C-III, Putney Inc., Portland, Me., USA) was given intramuscularly. Anesthesia was induced with isoflurane inhalation (Isothesia ${ }^{\circledR}$, Butler Schein Animal Health, Memphis, Tenn., USA) via mask, and subsequently the animal was intubated. A 25-mg indomethacin suppository (Letco Medical, Decatur, Ala., USA) was placed rectally. The urinary bladder was emptied via a Foley catheter, which was left in place for the duration of the surgery. An intravenous catheter was placed into the left cephalic vein and blood was drawn for a complete blood cell count and a general chemistry profile (described below). Intravenous 5\% dextrose solution (Abbott Laboratories, Abbott Park, Ill., USA) with $\mathrm{MgSO}_{4}$ added at a concentration of 3,000 $\mathrm{mg} / 250 \mathrm{ml}$ was begun. The fluids were administered throughout the surgical procedure for a total volume of $75 \mathrm{ml}$ which provided a total dose of $900 \mathrm{mg}$ of $\mathrm{MgSO}_{4}$. The abdomen was then shaved and a surgical prep was performed. The animal was transported to the surgery suite, where it was placed in a supine position and a final skin prep was performed. Ampicillin and sulbactam (Unasyn ${ }^{\circledR}, 30$ mg/kg i.m., Sagent Pharmaceuticals, Shaumburg, Ill., USA) were administered prior to surgery, and buprenorphine hydrochloride (Buprenex ${ }^{\circledR}, 0.015 \mathrm{mg} / \mathrm{kg}$, Reckitt Benckiser Pharmaceuticals Inc., Richmond, Va., USA) was administered at the end of the surgery. After completion of surgery, the anesthesia was stopped, and once a swallowing reflex returned, the animal was extubated and returned to the home cage and monitored until it became sternal. The status of housed animals was constantly observed by staff personnel. Animals exhibiting signs of stress, depression, or abnormal behavior were evaluated and discussed with the facility supervisor and attending veterinarian. Postsurgically, the animals were evaluated several times a day and during the night. Oral indomethacin chews (25 mg, cherry or banana flavored; Peoples Custom Rx, Memphis, Tenn., USA) were given every $6 \mathrm{~h}$ for $48 \mathrm{~h}$, and Unasyn was given every $12 \mathrm{~h}$ for 3 days.

\section{Operative Technique}

Following orientation of the fetus and placenta in utero, a 22-gauge needle (Echotip disposable amniocentesis needle; Cook, Spencer, Ind., USA) was inserted into the amniotic cavity and sterile saline solution at $37^{\circ} \mathrm{C}$ was injected. Next, gentle external version was undertaken in order to bring the fetal snout to a surgically accessible area away from the placenta. A 14-gauge suprapubic trocar needle (Cook; Spencer) was inserted through a 5-mm skin incision into the amniotic cavity. After that, a guide wire was advanced through this needle into the amniotic cavity as described elsewhere [17]. The needle was withdrawn over the guide wire and then a thin-walled flexible Teflon cannula (10-Fr Check Flo ${ }^{\circledR}$ Cook; Bloomington, Ind., USA) loaded with a dilator was advanced over the guide wire (Seldinger technique). The cannula was directed towards the snout and the fetoscopic instruments were
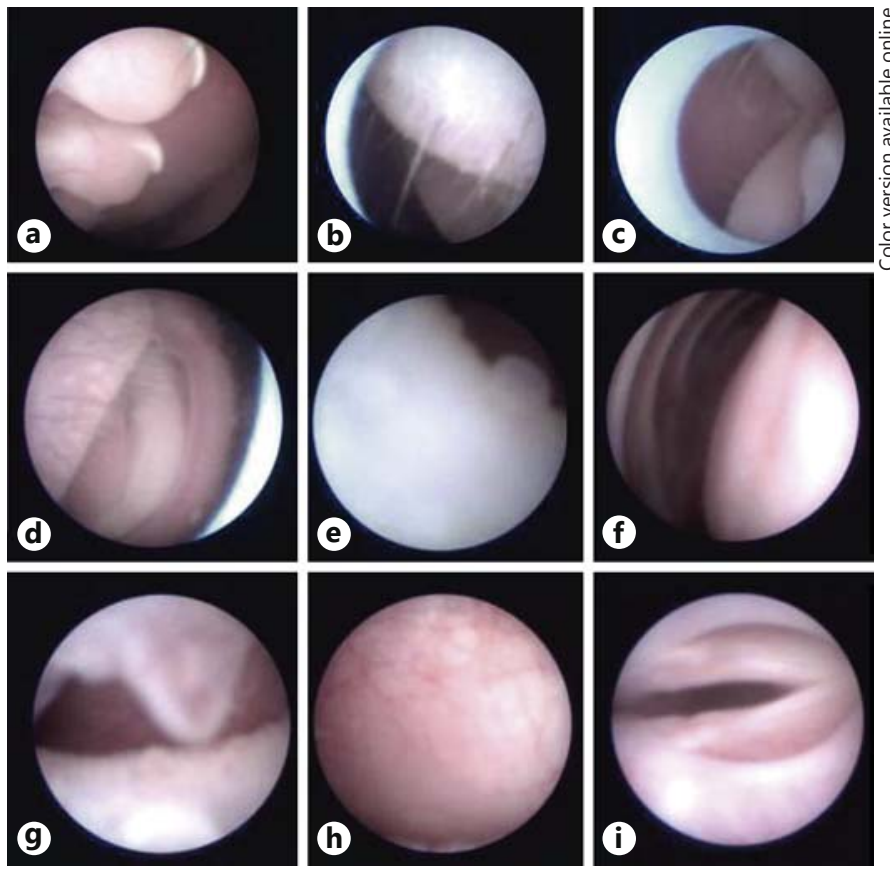

Fig. 1. Fetal endoscopic anatomy of the baboon. a Fingers. b Mouth with whiskers. c Lips and tongue. d Lips, tongue and mandible. e Back of the tongue. $\mathbf{f}$ Hard palate. $\mathbf{g}$ Frenulum. $\mathbf{h}$ Pharynx. i Vocal cords.

inserted. These instruments included a slightly bent 7-Fr sheath with a connection for amnioinfusion at body temperature. Next, a 1.3-mm 10,000-pixel fiber endoscope (Karl Storz, Tubingen, Germany) was introduced. The balloon occlusion system, consisting of a catheter (Baltacci ${ }^{\circledR}$, Balt Extrusion, Montmorency, France) loaded with a detachable valve balloon (GoldBal2 balloon, Balt Extrusion) was advanced through the sleeve (described in detail in Deprest et al. [18]). The fetoscope was connected to the light source and video recorder $(\times 8,000$ Light Source, SDC3, Stryker, San Jose, Calif., USA).

The landmarks were not as obvious as in humans. The nose was more difficult to find; therefore, the cannula was inserted at the level of the tip of the snout. The fetal extremities could at times be identified in front of the mouth (fig. 1a). Eventually, the hairs (whiskers or moustache) would identify the fetal parts and the upper lip (fig. 1b, c).

The endoscope was introduced into the fetal mouth and directed over the tongue (fig. 1d, e) along the midline by visualizing the raphe of the palate (fig. 1f) and uvula (fig. 1g), to the pharynx (fig. $1 \mathrm{~h}$ ) then to the larynx, with the epiglottis as a landmark, and finally through the vocal cords (fig. 1i) to the trachea (fig. 2a, b) and carina (fig. 2c). In the 3 animals that underwent balloon placement, the catheter was positioned to deliver the balloon just above the carina (fig. $2 \mathrm{~d}, \mathrm{e}$ ). Of the 4 animals that underwent the sham tracheoscopy, the balloon was inserted, but not inflated in one animal. In the 3 remaining animals, the balloon was not inserted. At the end of the procedure, the excessive amount of infused fluid was drained until the depth of the maximal pocket of the amniotic fluid did not exceed 3-4.5 $\mathrm{cm}$. 

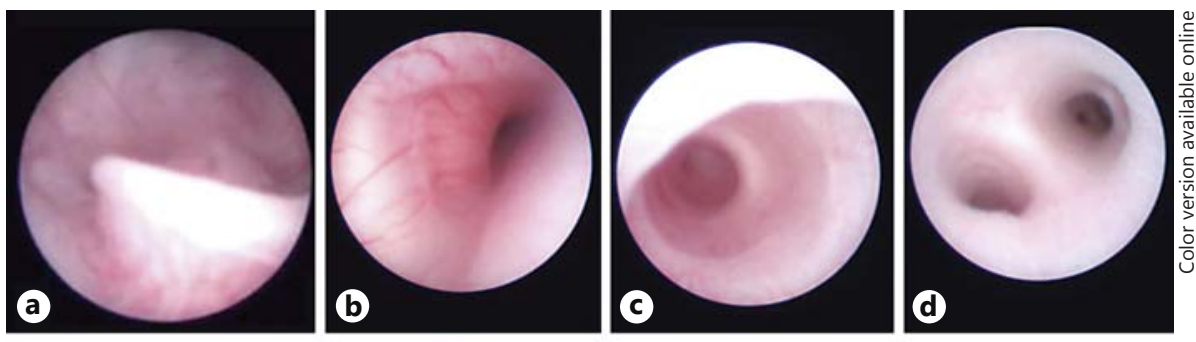

Fig. 2. Fetal endoscopic anatomy of the baboon. a Epiglottis. b Vallecular. c Trachea. d Carina. e Insertion of the balloon. $\mathbf{f}$ Tip of the inflated balloon. $\mathbf{g}$ Removal of the balloon.
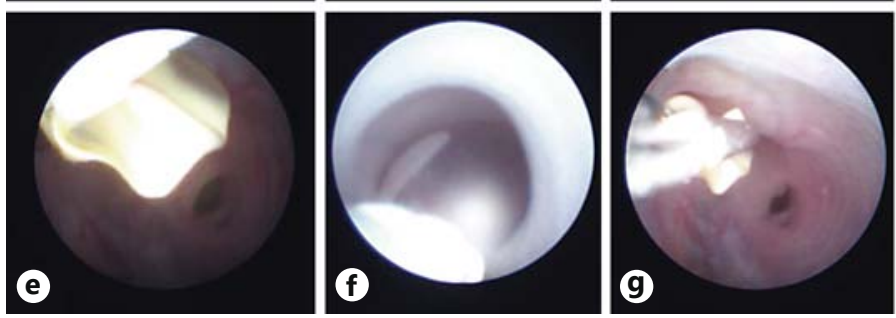

The second surgery was performed in the same manner. The balloon was endoscopically punctured with a sharp stylet (11506P Karl Storz) and the residuals of the balloon were removed using a 3 -Fr grasping forceps (11510C Karl Storz; fig. 2f). In one animal, the balloon was punctured under ultrasound guidance.

\section{Complete Blood Count and Biochemical Indices}

Prior to each surgical procedure, $20 \mathrm{ml}$ of maternal blood was obtained, processed as previously described [19] and included a complete blood count (CBC) and serum chemistries, described by Schlabritz-Loutsevitch et al. [19] (Antech Diagnostic, Southaven, Miss., USA).

\section{Adrenocorticotropic Hormone and $\beta$-Endorphin Evaluation}

To evaluate the maternal stress prior to the procedure, adrenocorticotropic hormone (ACTH) was measured in serum using an immunoassay kit (ALPCO Diagnostic, No. 21-ACTHU-E01, Salem, N.H., USA). All measurements were performed in triplicate. Intraassay validation for immunoassay was $2.27-6.71 \%$. The ACTH ELISA has a calculated sensitivity of $0.22 \mathrm{pg} / \mathrm{ml}$. The $\beta$-endorphin was measured in serum using an immunoassay kit [Peninsula Laboratories, LLC, San Carlos, Calif., USA, No. S-1245, $\beta$-endorphin (bovine, camel, mouse)]. All measurements were performed in duplicate. The sensitivity (Av. IC50) of the assay is $0.29 \mathrm{ng} / \mathrm{ml}$. Intraassay coefficient of variance was $0.4 \%$.

\section{Newborn Procedures}

Within $24 \mathrm{~h}$ after delivery, the dam was sedated with i.m. ketamine (10 mg/kg, Putney Ketamine $\mathrm{HCl}$ for Injection C-III; Putney Inc.). The neonate was transported to the imaging suite, where it was examined and weighed without anesthesia. At all times, every effort was made to keep the neonate warm by wrapping it in blankets and providing external heat. Next, the neonate was anesthetized via a facemask with 1-2\% isoflurane for the $\mathrm{X}$-ray examination.

\section{$X$-Ray Examination of the Newborn}

The X-ray imaging was performed using a veterinary digital radiograph machine (Sedecal, Buffalo Grove, Ill., USA). The images were taken in lateral and $\mathrm{AP}$ positions, using a $60 \mathrm{kVp}$ and
$3.2 \mathrm{~mA}$ for both. The images were analyzed after being placed into an IDEXX-PACS Imaging system (IDEXX Laboratories, Inc., Minnesota, Minn., USA). The tracheal width (diameter) was measured at the level of the thoracic inlet just above the carina and at the mid-distance between the above-mentioned points [20]. The combined (average tracheal) width was calculated. Additionally, the maximal diameter of the trachea was measured at a site of the trachea within the upper chest cavity.

\section{Ultrasound Examinations}

Ultrasound examinations were performed as described previously [21,22] for fetal morphometry and Doppler evaluation of the pulsatility indices (PI) of fetal middle cerebral artery (MCA), ductus venosus, ductus arteriosus, pulmonary artery, uterine artery, umbilical artery, using a Samsung A30 machine (Samsung, Samsung Medison Co., Ltd., Ridgefield Park, N.J., USA).

\section{Statistical Analyses}

Statistical analyses were performed using the ANOVA and Kruskal-Wallis tests. We applied Friedman analysis to calculate changes in the variables over time to compare mean maternal biochemical, $\mathrm{CBC}$ parameters and stress axis hormones between first and second surgeries and between FETO and S-FETO groups. Significance was set at $p<0.05$. Data are presented as mean \pm SEM, unless indicated differently.

\section{Results}

\section{Surgery Characteristics}

There was no difference in duration of the FETO and S-FETO surgeries, neither at the first, nor at the second time point $(2.61 \pm 0.89$ and $3.6 \pm 0.14$ vs. $2.12 \pm 0.37$ and $2.29 \pm 0.23 \mathrm{~h}$, respectively). The duration of the second surgery was significantly reduced compared to the first operation in the S-FETO group, associated with only the 
Fig. 3. Placenta and fetus of the animal who delivered post-term infant. a-c Notice the well-developed fetus, area of necrosis and yellow discoloration of placenta. d The length of the trachea from the vocal cords to carina.
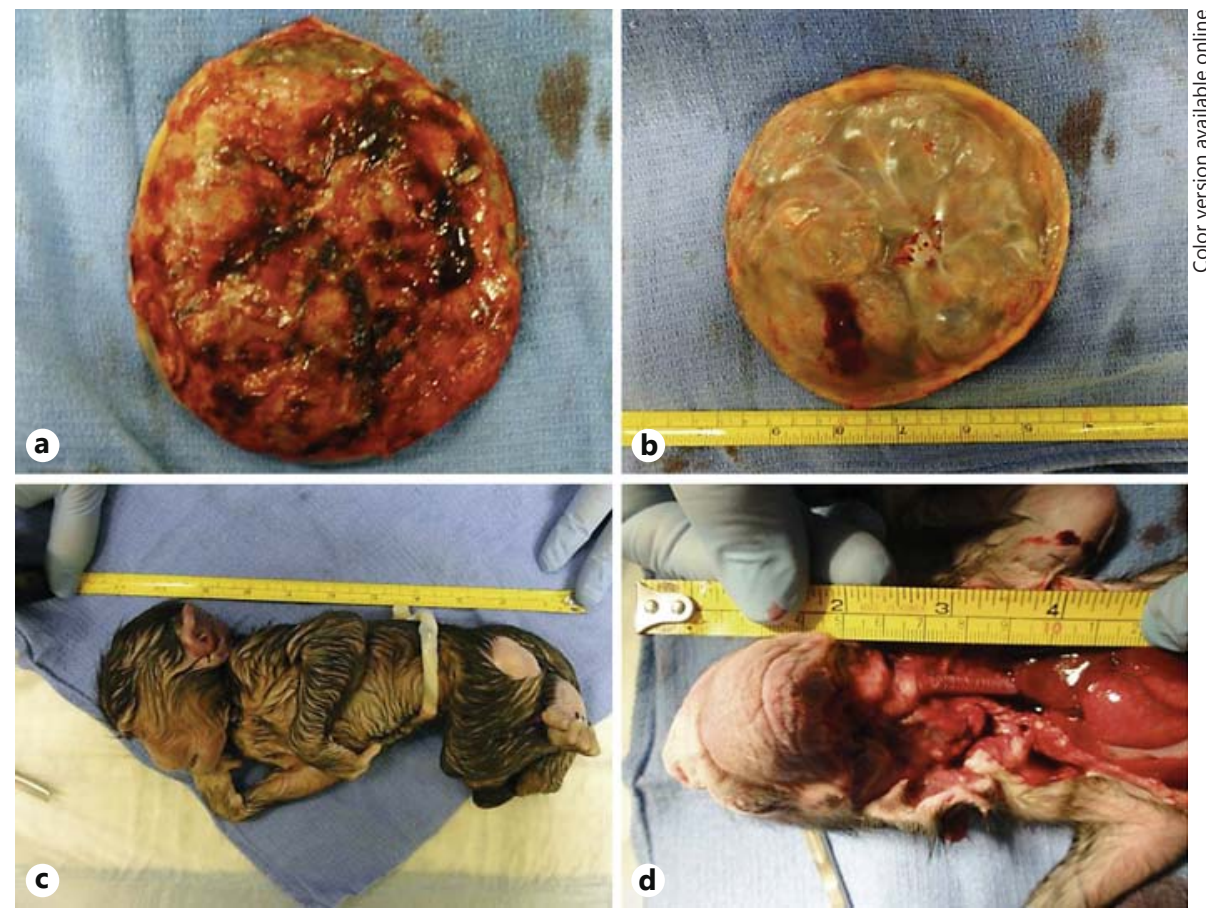

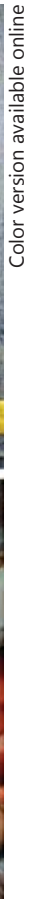

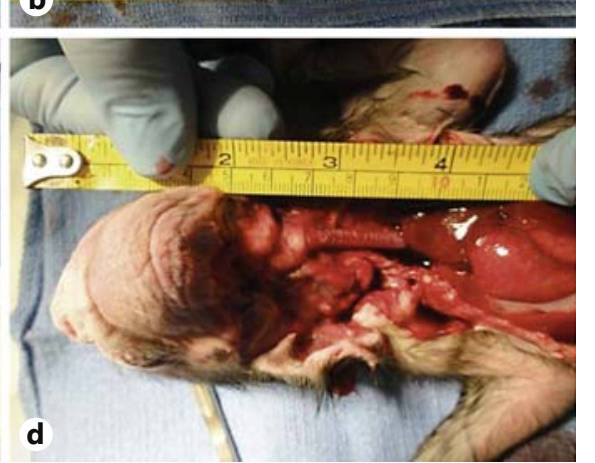

tracheal visualization as compared to balloon placement in these animals.

The total volume of saline solution used for the amnioinfusion to improve visualization during the procedure was $396.3 \pm 201$ and $740.0 \pm 239.0 \mathrm{ml}$ during the balloon placement surgery in FETO and S-FETO groups, respectively. During the second set of surgeries (balloon retrieval), one animal had amniorrhexis at the beginning of the procedure. Due to amniorrhexis, the amount of the saline solution used for the visualization and irrigation of the amniotic cavity in this baboon $(2,900 \mathrm{ml})$ exceeded the amount infused during the second procedure in the rest of the animals in both groups (range 270-1,050 ml).

\section{Maternal and Fetal Outcome}

The average pregnancy duration in the FETO group did not differ from the animals in the S-FETO group $(90.0 \pm 1$ vs. $98.4 \pm 6 \%)$. One animal in the S-FETO group went over term (200 dGA), which resulted in stillbirth (fig. 3). Neonatal weights did not differ between the two groups ( $830.0 \pm 129$ vs. $723.7 \pm 65 \mathrm{~g}$, respectively). One preterm infant in the S-FETO group was delivered at 153 dGA (5 days after the first sham operation). It was hand reared and developed normally (fig. $4 \mathrm{~d}-\mathrm{f}$ ).

In one animal from the S-FETO group, which underwent insertion, but not the inflation of the balloon, the re- siduals of the balloon were detected in the trachea during $\mathrm{X}$-ray evaluation and was successfully removed using a conventional laryngoscope and an endoscopic extractor (fig. $4 a-c)$.

\section{Ultrasound Parameters}

The ultrasound indices of fetal growth and blood flow are presented in table 2 . There were no differences in maternal and fetal blood flow indices prior to and after the endoscopic interventions in both groups.

\section{$C B C$ and Biochemical Parameters}

Maternal blood biochemical parameters did not differ between the two groups with the exception of the concentrations of alkaline phosphatase, which was increased in the FETO group compared to S-FETO group prior to the first and second surgeries (114 \pm 12 vs. $71.7 \pm 5 \mathrm{U} / \mathrm{l}$ and $119.3 \pm 13.0$ vs. $78 \pm 9.6 \mathrm{U} / \mathrm{l})$.

\section{ACTH and $\beta$-Endorphins}

The ACTH concentrations did not differ between the FETO and S-FETO groups prior to the first (30.7 \pm 19 and $23.2 \pm 15 \mathrm{pg} / \mathrm{ml}$, respectively) and second procedures ( $33.7 \pm 5$ and $22.2 \pm 4 \mathrm{pg} / \mathrm{ml}$, respectively). The $\beta$-endorphin concentration did not differ in the FETO as compared to the S-FETO groups prior to the first procedure $(0.560 \pm$ 

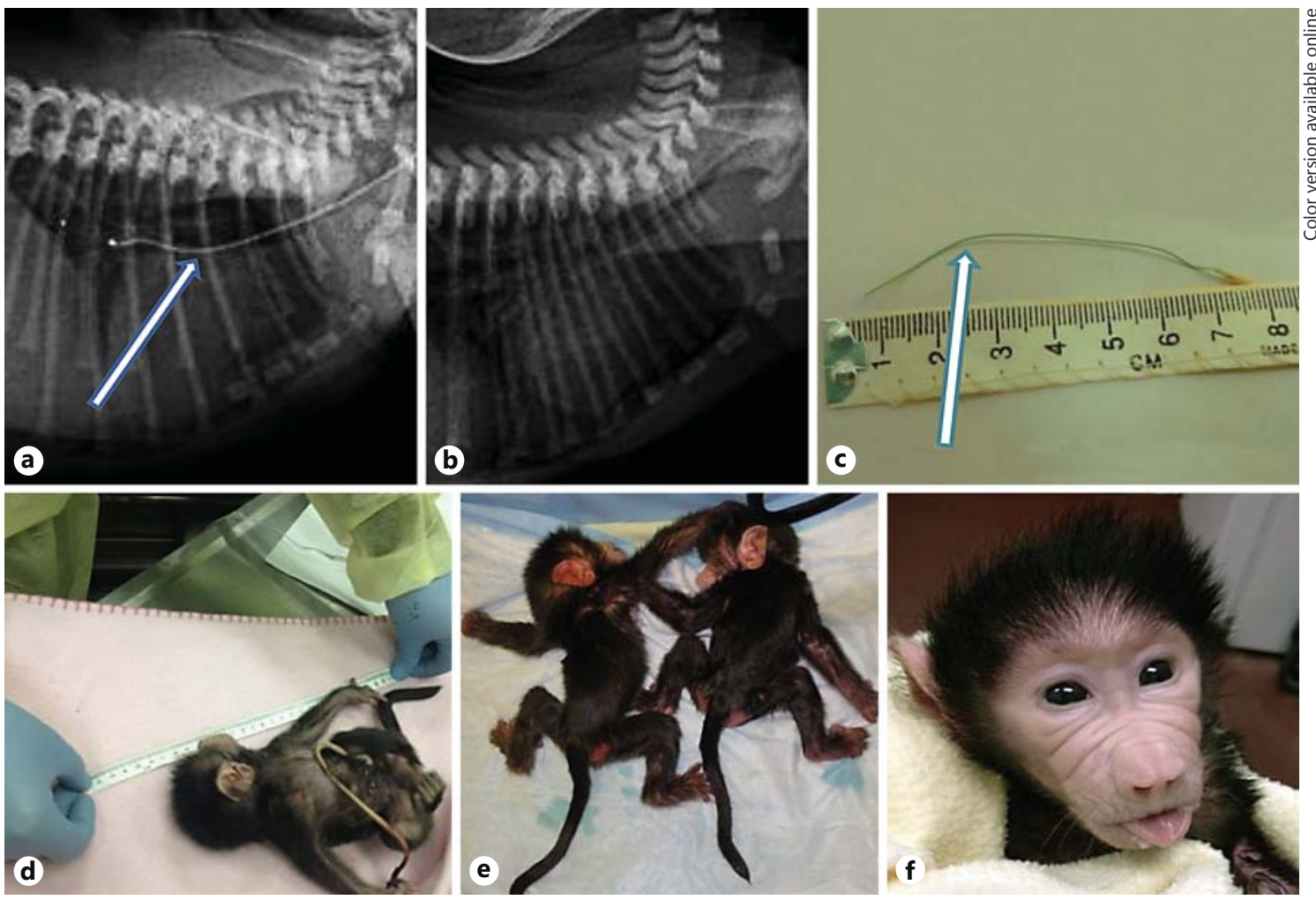

Fig. 4. Residuals of the balloon in the S-FETO animal prior to removal (a), after removal (b), and gross photo (c). d Preterm infant born in the S-FETO group at delivery (153 dGA). e Same infant at equivalent of $163 \mathrm{dGA}$ (left), compared to the healthy newborn at $163 \mathrm{dGA}$ (right), and at f equivalent of $171 \mathrm{dGA}$.

0.025 and $0.752 \pm 0.109 \mathrm{ng} / \mathrm{ml}$, respectively) and to the second procedure $(0.787 \pm 0.013$ and $0.939 \pm 0.033 \mathrm{ng} / \mathrm{ml}$, respectively; data are presented as mean $\pm \mathrm{SD}$ ).

\section{$X$-Ray Evaluation}

The maximal tracheal width was $7.02 \pm 0.6 \mathrm{~mm}$ in the FETO group versus $5.46 \pm 0.6 \mathrm{~mm}$ in the S-FETO group (fig. 5).

\section{Discussion}

NHP have been proven to be an ideal model to study fetal and postnatal lung maturation [14]; however, in NHP the development of fetal interventions with fetal survival has been practically nonexistent due to the high risk of preterm deliveries and complications [23-25]. Despite the fact that the natural occurrence of such pregnancy-related complications as stillbirths and placenta abruption cases in Old World NHP (baboons and macaques) are similar to humans [26-28], the differences

Percutaneous Fetoscopic Endoluminal Tracheal Occlusion in Baboons
Table 2. Ultrasound indices of fetal growth and blood flow prior to surgeries in pregnant baboons (Papio spp.)

\begin{tabular}{lcc}
\hline & FETO $(\mathrm{n}=3)$ & S-FETO $(\mathrm{n}=4)$ \\
\hline Biparietal diameter, cm & $5.1 \pm 0.1$ & $4.3 \pm 0.4$ \\
Head circumference, cm & $19.3 \pm 0.6$ & $16.6 \pm 1.4$ \\
Abdominal circumference, cm & $16.8 \pm 0.7$ & $13.4 \pm 1.4$ \\
Femur length, cm & $4.2 \pm 0.1$ & $3.5 \pm 0.4$ \\
Amniotic fluid index, cm & $5.3 \pm 2.2$ & $4.4 \pm 1.3$ \\
Fetal heart rate, bpm & $148.4 \pm 2.4$ & $148.0 \pm 7.9$ \\
\hline PI* & & \\
MCA & $1.67 \pm 0.1$ & $1.4 \pm 0.3$ \\
Ductus venosus & $0.99 \pm 0.4$ & $0.37(\mathrm{n}=1)$ \\
Ductus arteriosus & $2.64 \pm 0.4$ & $2.36 \pm 0.02$ \\
Pulmonary artery & $2.55 \pm 0.4$ & $2.41 \pm 0.4$ \\
Uterine artery & $1.38 \pm 0.3$ & $1.61 \pm 0.39$ \\
Umbilical artery & $1.39 \pm 0.1$ & $1.52 \pm 0.1$ \\
\hline Fetal lung measurements & & \\
Area, cm ${ }^{2}$ & & \\
$\quad$ Left & & \\
$\quad$ Right & $1.89 \pm 0.4$ & $1.37 \pm 0.3$ \\
Circumference, cm $\quad$ Left & $2.75 \pm 0.15$ & $1.51 \pm 0.2$ \\
$\quad$ Right & $6.0 \pm 0.11$ & $5.44 \pm 0.8$ \\
\hline
\end{tabular}

* PI = Pulsatility index. 
Fig. 5. Representative radiographs of the tracheal width in the newborn after FETO procedure (a) compared to the S-FETO (sham operation) animal (b).
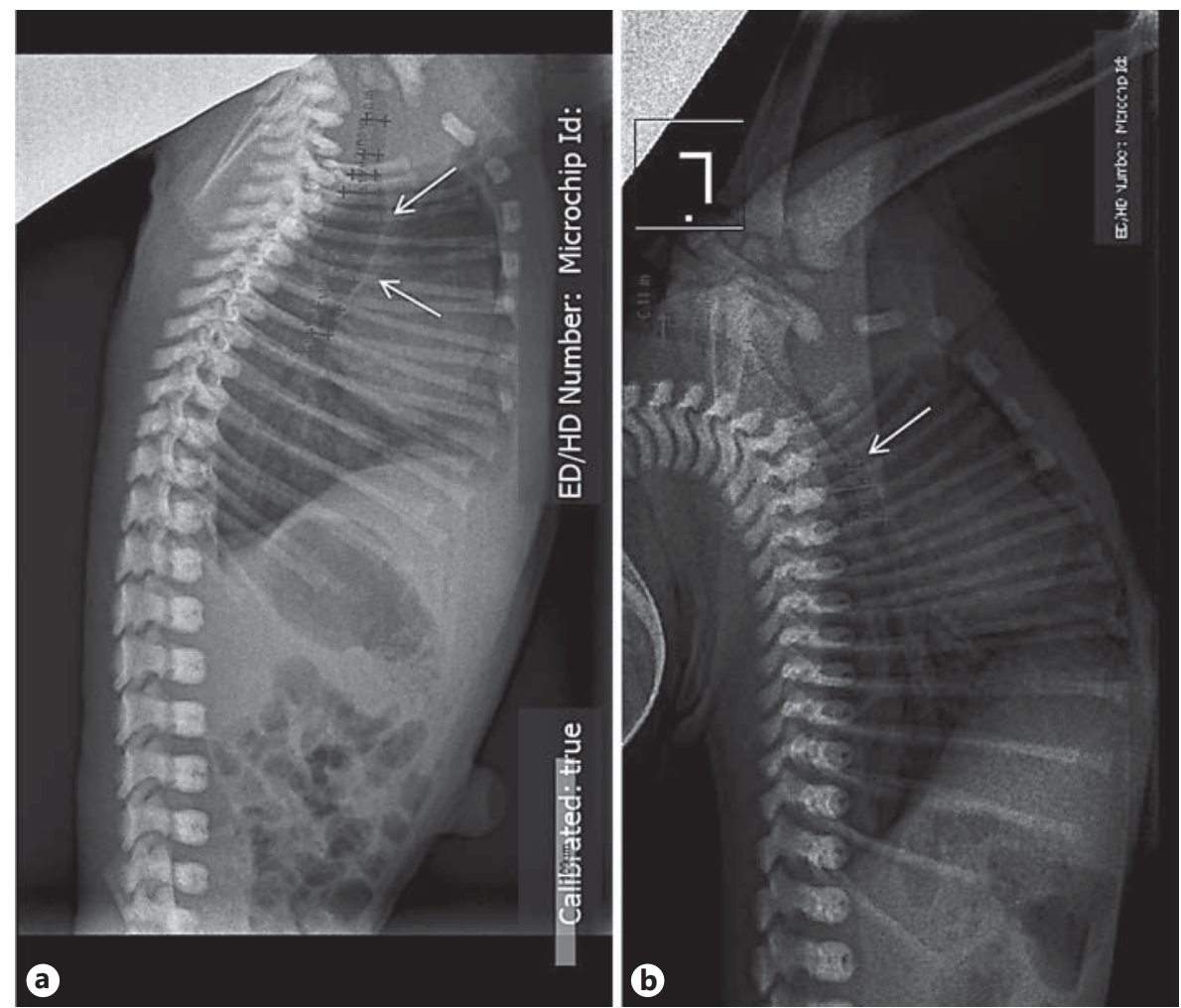

between NHP and humans including shallow trophoblast invasion, decreased amount of amniotic fluid in the third trimester, the mechanism of labor [13], and myometrial thickness [27], might be the reason behind the reported increased complication rate and technical difficulties in NHP. Interestingly, van der Wildt et al. [25] found the absence of myometrial electrical activity in rhesus monkeys after simple fetoscopic manipulations.

To ensure the decrease in fetal mortality and decrease incidence of preterm labor in NHP, 'the precise adjustment of maternal anesthesia and tocolytics are required' $[29,30]$. Nakagawa et al. [31] reported the fetal loss in monkeys which underwent fetal surgeries to be between 6.7 and $50 \%$, where the risk of complications was dependent on the degree of surgical manipulations [25, 32]. Feitz et al. $[23,24]$ were able to establish the macaque model for endoscopic fetal manipulation of the urogenital tract, while Mattison and King [33] reported the percentage of fetal loss in macaques as high as $52.4 \%$ with major complications including maternal hemorrhage into the amniotic fluid, inability to enter the amniotic cavity, and abortion.

Amniorrhexis is another important complication of FETO and subsequent early preterm delivery with the risk reported to be more than $35 \%$ in humans [34]. This risk appears to decrease with the experience of the operator; however, it could not be totally eliminated [34]. In our study, there was only one case that was complicated by amniorrhexis. In this case, the surgery was performed at $163 \mathrm{dGA}$ (it was a second surgery in the S-FETO group). This gestational age is defined as 'at term' in baboons [28]. The animal was close to delivery as indicated by vaginal discharge, position of fetal head and cervical opening at the ultrasound evaluation.

Tracheomegaly has been described in human fetuses undergoing FETO [20,35-37]. In humans this effect has been linked to the coexistence of the hypoplastic bronchial tree [38] and the effect of the occlusion itself [36, 39]. In our experiments, the duration of the occlusion (3-4 weeks or $15.4 \%$ of the duration of gestation) was comparable to what was reported in humans $(6-22.5 \%$ of the duration of gestation) [20]. The tracheal diameter in the baboon fetuses was within the lower range documented for the preterm human fetuses [20] and the dimensions of the balloon used in our experiments were the same as published for human fetuses $(7 \mathrm{~mm}$ in width and $20 \mathrm{~mm}$ in length). In humans, the tracheomegaly could persist up to 5 years postnatally $[36,40]$. The observation of the same complication in the baboons opens the pioneering
Mari et al. 
opportunity not reported in other animal models to unveil the mechanisms and develop the prevention and treatment strategies in case of this complication.

The procedure itself did not influence the maternal long-term HPA axis in our study. This observation is important since this pathway is closely involved in the mechanisms of parturition as well as in the process of lung maturation [41].

The PI of ductus venosus blood flow in the reported experiments was higher than those reported by us for the baboons at the same gestational age [42], but similar to those published for human fetuses [31]. The uterine artery PI was higher than estimated by some authors [43], but within the range reported by others [22]. These discrepancies could be due to the differences in the animal position, type of the anesthesia, and animal housing (indoor vs. outdoor). The PI of umbilical artery and MCA were within the range published for baboons $[22,43]$.

The application of the baboon model opens a new venue for the development of the adjuvant treatment of CDH. For example, the tracheal occlusion increased leptin expression in the experimental animal model [44]; however, leptin treatment in mice and sheep failed to stimulate lung development [45]. The latest could be due to the fact that leptin metabolism in pregnancy differs between human and ru- minants or rodents. The leptin lung endocrinology in baboons is similar to humans [46], and leptin therapy might be beneficial in this model. The same might be true for other regulatory mechanisms and novel therapeutic targets.

In summary, the use of the closest to human animal models to study fetal pathophysiology and development of techniques of fetal intervention is imperative for the success of fetal care. Thus, the description in the present study of the feasibility of repeated fetal interventions in baboons (Papio spp.) opens new horizons to the understanding and treatment of fetal anomalies.

\section{Acknowledgement}

The authors would like to thanks Dr. M. Landers, Ms. Stacey Barnett and Ms. Ernestine Hayes who were instrumental for the success of the experimental surgeries. The support of the technical personnel of the Oklahoma Primate Center: Tommy Holbrook, BS, LATG; Aaron Admire, BS, LAT; Sam Cook, BA; Gail Goodson, LAT, and Tammy McKnight, LAT, is highly appreciated. Grant support: 2 P40 OD01098-15 from the Office of the Director National Institutes of Health to G.W. Authors are thankful to Dr. Ramona Phinehas for her excellent help with animal sampling, assays and manuscript editing. The content of this article is solely the responsibility of the authors and does not necessarily represent the official views of the National Institutes of Health.

\section{References}

$\checkmark 1$ Keijzer R, Puri P: Congenital diaphragmatic hernia. Semin Pediatr Surg 2010;19:180-185.

-2 Colvin J, Bower C, Dickinson JE, Sokol J: Outcomes of congenital diaphragmatic hernia: a population-based study in Western Australia. Pediatrics 2005;116:e356-e363.

3 de Buys Roessingh AS, Dinh-Xuan AT: Congenital diaphragmatic hernia: current status and review of the literature. Eur J Pediatr 2009; 168:393-406.

4 Dekoninck P, Gratacos E, Van Mieghem T, Richter J, Lewi P, Ancel AM, Allegaert K, Nicolaides K, Deprest J: Results of fetal endoscopic tracheal occlusion for congenital diaphragmatic hernia and the set up of the randomized controlled TOTAL trial. Early Hum Dev 2011;87:619-624.

$\checkmark 5$ Lipsett J, Cool JC, Runciman SC, Ford WD, Parsons DW, Kennedy JD, Martin AJ: Effect of immediate versus slow intrauterine reduction of congenital diaphragmatic hernia on lung development in the sheep: a morphometric analysis of term pulmonary structure and maturity. Pediatr Pulmonol 2000;30: 228-240.

-6 Aubry E, Fayoux P, Jani J, Deprest J, Deruelle P, Houfflin-Debarge V, Storme L: Tracheal occlusion alters pulmonary circulation in the fetal lamb with normally developing lungs. J Pediatr Surg 2013;48:481-487.

-7 Mesas-Burgos C, Nord M, Didon L, Eklof AC, Frenckner B: Gene expression analysis after prenatal tracheal ligation in fetal rat as a model of stimulated lung growth. J Pediatr Surg 2009; 44:720-728.

-8 Maltais F, Seaborn T, Guay S, Piedboeuf B: In vivo tracheal occlusion in fetal mice induces rapid lung development without affecting surfactant protein C expression. Am J Physiol Lung Cell Mol Physiol 2003;284:L622-L632.

\9 Muensterer OJ, Flemmer AW, Bergmann F, Hajek KS, Lu HQ, Simbruner G, Deprest JA, Till H: Postnatal lung mechanics, lung composition, and surfactant synthesis after tracheal occlusion vs prenatal intrapulmonary instillation of perfluorocarbon in fetal rabbits. J Pediatr Surg 2005;40:26-31.

10 Khan PA, Cloutier M, Piedboeuf B: Tracheal occlusion: a review of obstructing fetal lungs to make them grow and mature. Am J Med Genet C Semin Med Genet 2007;145C:125-138.

-11 Malli F, Papaioannou AI, Gourgoulianis KI, Daniil Z: The role of leptin in the respiratory system: an overview. Respir Res 2010;11:152.

12 Schlabritz-Loutsevitch NE, Lopez-Alvarenga JC, Comuzzie AG, Miller MM, Ford SP, Li C,
Hubbard GB, Ferry RJ Jr, Nathanielsz PW: The prolonged effect of repeated maternal glucocorticoid exposure on the maternal and fetal leptin/insulin-like growth factor axis in Papio species. Reprod Sci 2009;16:308-319.

13 Schlabritz-Loutsevitch N, Ballesteros B, Dudley C, Jenkins S, Hubbard G, Burton GJ, Nathanielsz P: Moderate maternal nutrient restriction, but not glucocorticoid administration, leads to placental morphological changes in the baboon (Papio sp.). Placenta 2007;28:783-793.

14 Coalson JJ, Winter VT, Siler-Khodr T, Yoder BA: Neonatal chronic lung disease in extremely immature baboons. Am J Respir Crit Care Med 1999;160:1333-1346.

15 Joy SD, O’Shaughnessy R, Schlabritz-Loutsevitch N, Leland MM, Frost P, Fan-Havard P. Fetal blood sampling in baboons (Papio spp.): important procedural aspects and literature review. J Med Primatol 2009;38:151155.

16 Van Calsteren K, Devlieger R, De Catte L, D'Hooghe T, Chai DC, Mwenda JM, Vergote I, Amant F: Feasibility of ultrasound-guided percutaneous samplings in the pregnant baboon: a model for studies on transplacental transport. Reprod Sci 2009;16:280-285.
Percutaneous Fetoscopic Endoluminal Tracheal Occlusion in Baboons
Fetal Diagn Ther 2014;35:92-100 DOI: $10.1159 / 000357139$ 
17 Deprest JA, Van Schoubroeck D, Van Ballaer PP, Flageole H, Van Assche FA, Vandenberghe K: Alternative technique for Nd:Yag laser coagulation in twin-to-twin transfusion syndrome with anterior placenta. Ultrasound Obstet Gynecol 1998;11:347-352.

-18 Deprest J, Nicolaides K, Done E, Lewi P, Barki G, Largen E, Dekoninck P, Sandaite I, Ville Y, Benachi A, Jani J, Amat-Roldan I, Gratacos E: Technical aspects of fetal endoscopic tracheal occlusion for congenital diaphragmatic hernia. J Pediatr Surg 2011;46:22-32.

19 Schlabritz-Loutsevitch NE, Hubbard GB, Jenkins SL, Martin HC, Snider CS, Frost PA, Leland M, Havill LM, McDonald TJ, Nathanielsz PW: Ontogeny of hematological cell and biochemical profiles in maternal and fetal baboons (Papio species). J Med Primatol 2005; 34:193-200.

-20 Jani J, Valencia C, Cannie M, Vuckovic A, Sellars M, Nicolaides KH: Tracheal diameter at birth in severe congenital diaphragmatic hernia treated by fetal endoscopic tracheal occlusion. Prenat Diagn 2011;31:699-704.

21 Mari G, Hanif F: Fetal Doppler: umbilical artery, middle cerebral artery, and venous system. Semin Perinatol 2008;32:253-257.

22 Schlabritz-Loutsevitch N, Tchirikov M, Jenkins SL, Nathanielsz PW: Uterine, umbilical and middle cerebral artery Doppler measurements in pregnant baboons and their fetuses at 90, 144 and 175 days gestation. J Soc Gynecol Invest 2004;11:90A

-23 Feitz WF, Steegers EA, Aarnink RG, Arts T, De Vries JD, Van der Wildt B: Endoscopic intrauterine fetal therapy: a monkey model. Urology 1996;47:118-119.

24 Feitz WF, Steegers EA, de Gier RP, Aarnink RG, Arts T, van der Wildt B: Feasibility of minimally invasive intrauterine fetal access in a monkey model. J Urol 1999;161:281285.

25 van der Wildt B, Luks FI, Steegers EA, Deprest JA, Peers KH: Absence of electrical uterine activity after endoscopic access for fetal surgery in the rhesus monkey. Eur J Obstet Gynecol Reprod Biol 1995;58:213-214.

-26 Schenone MH, Schlabritz-Loutsevitch N, Zhang J, Samson JE, Mari G, Ferry RJ Jr, Hubbard GB, Dick EJ Jr: Abruptio placentae in the baboon (Papio spp.). Placenta 2012;33:278284.
27 Schlabritz-Loutsevitch N, Hubbard G, Zhang J, Gupta S, Dick E Jr: Recurrent abruptio placentae in a cynomolgus monkey (Macaca fascicularis). Placenta 2013;34:388-390.

28 Sesbuppha W, Chantip S, Dick EJ Jr, Schlabritz-Loutsevitch NE, Guardado-Mendoza R, Butler SD, Frost PA, Hubbard GB: Stillbirths in Macaca fascicularis. J Med Primatol 2008;37:169-172.

29 Santolaya-Forgas J, Romero R, Mehendale R: The effect of continuous morphine administration on maternal plasma oxytocin concentration and uterine contractions after open fetal surgery. J Matern Fetal Neonatal Med 2006; 19:231-238.

30 Tame JD, Abrams LM, Ding XY, Yen A, Giussani DA, Nathanielsz PW: Level of postoperative analgesia is a critical factor in regulation of myometrial contractility after laparotomy in the pregnant baboon: implications for human fetal surgery. Am J Obstet Gynecol 1999; 180:1196-1201

- 31 Nakagawa K, Tachibana D, Nobeyama H, Fukui M, Sumi T, Koyama M, Ishiko O, Hecher $\mathrm{K}$ : Reference ranges for time-related analysis of ductus venosus flow velocity waveforms in singleton pregnancies. Prenat Diagn 2012;32: 803-809.

32 Luks FI, Deprest JA, Peers KH, Steegers EA, van der Wildt B: Gelatin sponge plug to seal fetoscopy port sites: technique in ovine and primate models. Am J Obstet Gynecol 1999; 181:995-996.

33 Mattison DR, King JC: Development of a nonhuman primate model for fetoscopy. J Med Primatol 1983;12:319-330.

-34 Deprest J, Jani J, Gratacos E, Vandecruys H, Naulaers G, Delgado J, Greenough A, Nicolaides K: Fetal intervention for congenital diaphragmatic hernia: the European experience. Semin Perinatol 2005;29:94-103.

- 35 Enriquez G, Cadavid L, Garces-Inigo E, Castellote A, Piqueras J, Peiro JL, Carreras E: Tracheobronchomegaly following intrauterine tracheal occlusion for congenital diaphragmatic hernia. Pediatr Radiol 2012;42:916922.

6 Deprest J, Breysem L, Gratacos E, Nicolaides K, Claus F, Debeer A, Smet MH, Proesmans M, Fayoux P, Storme L: Tracheal side effects following fetal endoscopic tracheal occlusion for severe congenital diaphragmatic hernia. Pediatr Radiol 2010;40:670-673.
37 Breysem L, Debeer A, Claus F, Proesmans M, De Keyzer F, Lewi P, Allegaert K, Smet MH, Deprest J: Cross-sectional study of tracheomegaly in children after fetal tracheal occlusion for severe congenital diaphragmatic hernia. Radiology 2010;257:226-232.

38 Nose K, Kamata S, Sawai T, Tazuke Y, Usui N, Kawahara H, Okada A: Airway anomalies in patients with congenital diaphragmatic hernia. J Pediatr Surg 2000;35:1562-1565.

39 Fayoux P, Hosana G, Devisme L, Deprest J, Jani J, Vaast P, Storme L: Neonatal tracheal changes following in utero fetoscopic balloon tracheal occlusion in severe congenital diaphragmatic hernia. J Pediatr Surg 2010;45: 687-692.

40 McHugh K, Afaq A, Broderick N, Gabra HO, Roebuck DJ, Elliott MJ: Tracheomegaly: a complication of fetal endoscopic tracheal occlusion in the treatment of congenital diaphragmatic hernia. Pediatr Radiol 2010;40: 674-680.

41 Grier DG, Halliday HL: Effects of glucocorticoids on fetal and neonatal lung development. Treat Respir Med 2004;3:295-306.

42 Tchirikov M, Schlabritz-Loutsevitch N, Nathanielsz PW, Beindorff N, Schroder HJ: Ductus venosus shunting in marmoset and baboon fetuses. Ultrasound Obstet Gynecol 2005;26:252-257.

43 Aberdeen GW, Baschat AA, Harman CR, Weiner CP, Langenberg PW, Pepe GJ, Albrecht ED: Uterine and fetal blood flow indexes and fetal growth assessment after chronic estrogen suppression in the second half of baboon pregnancy. Am J Physiol Heart Circ Physiol 2010;298:H881-H889.

-44 Boucherat O, Benachi A, Chailley-Heu B, Franco-Montoya ML, Elie C, Martinovic J, Bourbon JR: Surfactant maturation is not delayed in human fetuses with diaphragmatic hernia. PLoS Med 2007;4:e237.

45 Sato A, Schehr A, Ikegami M: Leptin does not influence surfactant synthesis in fetal sheep and mice lungs. Am J Physiol Lung Cell Mol Physiol 2011;300:L498-L505.

46 Henson MC, Swan KF, Edwards DE, Hoyle GW, Purcell J, Castracane VD: Leptin receptor expression in fetal lung increases in late gestation in the baboon: a model for human pregnancy. Reproduction (Cambridge) 2004; 127:87-94. 